\title{
First synthesis of silicon nanocrystals in amorphous silicon nitride from a preceramic polymer
}

\author{
M Biesuz ${ }^{1}$ Q P Bettotti ${ }^{2}$, S Signorini $^{2}$, M Bortolotti $^{1}$, R Campostrini $^{1}$, \\ M Bahri ${ }^{3}$, Orsen $^{3}$, G Speranza ${ }^{1,4,5}$, A Lale $^{6}$, S Bernard $^{6}$ and \\ G D Sorarù ${ }^{1}$ \\ ${ }^{1}$ University of Trento, Department of Industrial Engineering, Via Sommarive 9, I-38123 Trento, Italy \\ ${ }^{2}$ University of Trento, Department of Physics, Via Sommarive 14, I-38123 Trento, Italy \\ ${ }^{3}$ Institut de Physique et Chimie des Matériaux de Strasbourg (IPCMS), UMR 7504 CNRS-Université de \\ Strasbourg, 23 rue du Lœss, F-67034 Strasbourg cedex 2, France \\ ${ }^{4}$ CMM-FBK, Via Sommarive 18, I-38123 Trento, Italy \\ ${ }^{5}$ IFN-CNR, CSMFO Lab. \& FBK CMM, Via alla Cascata 56/C Povo, I-38123 Trento, Italy \\ ${ }^{6}$ Univ. Limoges, CNRS, IRCER, UMR 7315, F-87000, Limoges, France \\ E-mail: mattia.biesuz@unitn.it
}

\begin{abstract}
We report the first synthesis of silicon nanocrystals embedded in a silicon nitride matrix through a direct pyrolysis of a preceramic polymer (perhydropolysilazane). Structural analysis carried out by XRD, XPS, Raman and TEM reveals the formation of silicon quantum dots and correlates the microstructures with the annealing temperature. The photoluminescence of the nanocomposites was investigated by both linear and nonlinear measurements. Furthermore we demonstrate an enhanced chemical resistance of the nitride matrix, compared to the typical oxide one, in both strongly acidic and basic environments. The proposed synthesis via polymer pyrolysis is a striking innovation potentially allowing a mass-scale production nitride embedded $\mathrm{Si}$ nanocrystals.
\end{abstract}

Keywords: polymer pyrolysis, Si nanodots, silicon nitride, photoluminescence

\section{Introduction}

Technological evolution is steadily pushing the uses of silicon to new applications [1-3]. Silicon is the leading material in electronics [2], photovoltaic [2, 4, 5] and optical communications but new uses of properly engineered Si-based nanomaterials are projecting it into the themes of sensing materials [5-7], photocatalysis [5, 8], nonlinear optics [9-14], quantum technologies [15] and biomedics [5, 16-22]. One of the main drawback of silicon in photonics is its limited efficiency as light emitter, because of the indirect nature of its bandgap [5, 23, 24]. Yet properly engineered nanocrystalline $\mathrm{Si}$ (nc-Si), have partially overcome this limit and proof of concept of active Si-based photonics were demonstrated [2, 5, 23-41].

Most of the publications regarding nc-Si deal with systems where the nanodots are embedded in a silica matrix, nc$\mathrm{Si} @ \mathrm{SiO}_{2}$ [5, 11, 26, 31, 42-45]. However, such kind of microstructure presents some limits mainly in terms of chemical stability and refractive index value. In fact, silicon dioxide is corroded in both basic environments and hydrofluoric acid solutions; while the limited thermal stability of silicon dioxide forbids the application of nc-Si@a-SiO composites in applications where high power density are required (e.g. high pumping nonlinear optics regimes). 
Silicon nitride is a promising alternative for $\mathrm{nc}-\mathrm{Si}$ optoelectronic [30, 46-48], as it matches the optical transparency of oxide with an increased confinement effects, due to its larger refractive index. Moreover, $\mathrm{Si}$ nitride is both chemically and thermally more resistant than $\mathrm{SiO}_{2}$. Up to now, the fabrication methods of nc-Si in silicon nitride matrix rely mainly on physical deposition (e.g. thermal [47] or plasma enhanced $[9,10,30,49]$ chemical vapor deposition, electron beam evaporation [45], ion implantation and annealing [26]), others are of research interest only (like reactive evaporation [44], sputtering [29, 50, 51], laser ablation techniques [12]). However, all these technologies are characterized by a low yield, require complex instrumentations and are applicable to limited geometries (coatings/thin films). Furthermore, the formation of nc-Si in nitride required a much careful chose of the precursor mix and the interfacial stress at the nitride/substrate interface heavily limits the maximum thickness of the film [52] and it influences the optical properties of the nc-SI so that the origin of the photoluminescence (PL) emission is still unclear (e.g. see [52-55] and [56]).

The development of polymer-derived ceramics (PDCs) technology [57] offers new opportunities for the large scale production of nanostructures [58-61] and assures a great control over their chemical composition, thus enabling a fine tuning of the nanocrystals properties [7, 17] and, by enabling the processing of bulk materials, the polymer pyrolysis route allows bypassing the 'substrate/coating geometry' therefore avoiding the problem of interfacial stresses of the thin multilayer depositions. Thus it will help to clarify the origin of the PL coming from these nanocomposites. Among the different preceramic polymers reported in the literature [41-43], polysilazanes allow the formation of silicon nitride-based ceramics containing controlled free carbon and/or free silicon contents [58, 59, 62-65].

This work demonstrates the first synthesis of luminescent nc-Si in nitride matrix through the direct pyrolysis of a preceramic polymer: a polysilazane containing only $\mathrm{Si}, \mathrm{N}$ and $\mathrm{H}$, namely a perhydropolysilazane, is heated in a controlled atmosphere to induce the organic-to-inorganic [58, 59, 62, 63] transformation which leads to a $\mathrm{Si}-\mathrm{N}$ nanostructured ceramic material: nc-Si@a-SiN $x$, with $x, 4 / 3$ [58, 59]. Such an approach offers originality and innovation in the field of nc-Si technology and paves the way for a cheap and large-scale production of nanostructured nc-Si-containing ceramics with substantially no shape limitations; as a matter of fact, the PDCs process has already been applied to produce films, bulk materials and fibers [57].

\section{Experimental procedures}

A perhydropolysilazane (PHPS), constituted by linear chains of $\left(-\mathrm{SiH}_{2}-\mathrm{NH}-\right)$ units, was purchased from DurXtreme (NN120-20; DurXtreme, Uhlm, Germany) in a dibuthylether (DBE) solution (nominal composition: 20\% PHPS, $80 \%$ DBE). Before using the PHPS solution, DBE has been partially evaporated until a $80 \%$ PHPS $20 \%$ DBE solution was obtained. Pyrolysis of the pre-ceramic polymer was obtained using the furnace of a DTA/TGA Netzsch STA 409 instrument (Netzsch-Gerätebau GmbH, Selb, Germany) by loading about $150 \mathrm{mg}$ of PHPS solution into the alumina crucible. To perform the pyrolysis in a well-controlled atmosphere, air was removed from the furnace chamber by mean of a vacuum pump (till the pressure inside the furnace was $<0.1$ bar) and then the chamber was filled with Ar (purity 99.9999\%). This operation was repeated three times before each test. The thermal treatments were carried out setting a heating rate of $10{ }^{\circ} \mathrm{C} \mathrm{min}{ }^{-1}$ up to four different temperatures, namely $950^{\circ} \mathrm{C}, 1050^{\circ} \mathrm{C}, 1150^{\circ} \mathrm{C}$ and $1250^{\circ} \mathrm{C}$, with no dwelling time at high temperature, followed by free cooling. The Ar flux through the tubular furnace during the treatments was set to $50 \mathrm{~cm}^{3} \mathrm{~min}^{-1}$. An additional sample was produced at higher temperature to allow a complete crystallization of the amorphous matrix; such sample was treated, following the same procedures, up to $1400{ }^{\circ} \mathrm{C}$ with $2 \mathrm{~h}$ dwelling at high temperature.

Thermal gravimetric analysis coupled with mass spectrometry (TGA-MS) measurements were performed with a home-made interface which connect a LabSys Setaram thermobalance with a Trio1 VG quadrupole mass spectrometer. TG measurements were carried out fluxing the thermobalance furnace with a constant $120 \mathrm{~cm}^{3} \mathrm{~min}^{-1} \mathrm{He}$ flow. Samples were weighted and loaded into alumina crucible holders (volume $0.1 \mathrm{~cm}^{3}$ ), $\alpha-\mathrm{Al}_{2} \mathrm{O}_{3}$ was used as reference. Thermal analysis were carried out in the $20{ }^{\circ} \mathrm{C}-1000{ }^{\circ} \mathrm{C}$ range with a constant heating rate of $10^{\circ} \mathrm{C} \mathrm{min}{ }^{-1}$. During the thermal analysis an appropriate fraction of the purging He flux, was continuously withdrawn and analyzed by the mass detector by using a silica deactivate capillary column $(0.32 \mathrm{~mm}$ internal diameter, $13.5 \mathrm{~m}$ length) heated at $140{ }^{\circ} \mathrm{C}$. Electron mass spectra $(70 \mathrm{eV})$ were recorded with frequency of $1 \mathrm{scan} \mathrm{s}^{-1}$ in the $1-400$ amu range.

MS data were recorded as a continuous sequence of mass spectra. Any gas species released from the solid sample can be easily monitored by the detection of its fragmentation ion patterns leading to the total ion current (TIC) signal.

After pyrolysis the specimens were manually milled in an agate mortar. The obtained powders were characterized by $\mathrm{x}$ ray diffraction using an Italstructures IPD3000 diffractometer (Italstructures, Arco, Italy) equipped with a Co anode source (line focus) coupled with a multilayer monochromator on the incident beam and an Inel CPS120 detector on the diffracted beam. Diffraction data were collected in reflection geometry for $30 \mathrm{~min}$ and then modeled using the Maud [66] Rietveld software to extract quantitative information about crystalline phase composition and Si crystallite dimensions.

The composition and the chemical environments of the pyrolyzed samples were evaluated by $\mathrm{x}$-ray photoelectron spectroscopy (XPS). The spectra were collected using an Axis DLD Ultra spectrometer (Kratos-Manchester UK). Analyses are composed by wide scans on a BE energy range 1300 to $-5 \mathrm{eV}$ using a $160 \mathrm{eV}$ pass energy and high resolution (HR) core line spectra acquired at $20 \mathrm{eV}$ pass energy and setting the energy step at $0.05 \mathrm{eV}$. Charge compensation was needed to 


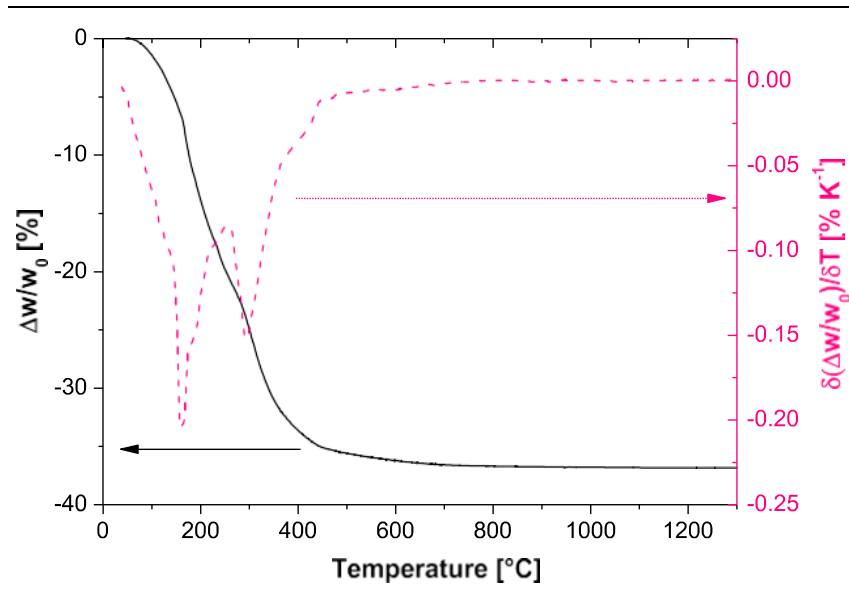

Figure 1. TGA and DTG plots of the $80 \mathrm{wt} \%$ PHPS in $20 \mathrm{wt} \%$ DBE solution (heating rate $=10^{\circ} \mathrm{C} \mathrm{m^{-1 }}$, Ar atmosphere).

acquire spectra on these non-conducting samples. Spectra were aligned on the binding energy scale taking the $\mathrm{C} 1 \mathrm{~s}$ at $284.6 \mathrm{eV}$ as a reference.

HR-scanning transmission electron microscopy (STEM) experiments were performed on a $\mathrm{C}_{\mathrm{s}}$-corrected JEOL $2100 \mathrm{~F}$ microscope operating at $200 \mathrm{KeV}$.

Both PL and Raman analysis were performed on a JobinIvon Aramis spectrophotometer, using a $532 \mathrm{~nm}$ laser as excitation source and a cooled CCD multichannel detector. Because of the rough powder surface, laser power has been adjusted on each measurement-with standard attenuation filters-to maximize either the PL or the Raman signal.

Third order nonlinear optical properties have been tested by measuring the PL stimulated by two photon absorption (TPA) processes. A pulsed laser (Katana HP by NKT Photonics) with $40 \mathrm{ps}$ pulses at $100 \mathrm{MHz}$ repetition rate, $0.9 \mathrm{~mm}$ spot diameter and with $1550 \mathrm{~nm}$ wavelength was used as source. The average power used was about $1 \mathrm{~W}$, i.e. $250 \mathrm{~W}$ of peak power, with $10 \mathrm{~nJ}$ energy per pulse. The bright visible PL emitted by the powders was recorded in reflection and directly coupled into an SMA optical fiber connected with a spectrometer (Ocean Optics 2000+).

Chemical resistance against both harsh acid and basic environments was tested by immersing the powders (50$100 \mu \mathrm{m})$ for $48 \mathrm{~h}$ in either $\mathrm{HF}(0.9 \mathrm{M})$ and $\mathrm{NaOH}(1 \mathrm{M})$. For each annealing temperature, a known amount of powder (about $10 \mathrm{mg}$ ) has been placed in a cuvette and immersed in the etching solution. After the etching, the powder was washed and centrifuge three times, before being weighted.

\section{Results}

Figure 1 shows the TGA plot of the PHPS solution we prepared, i.e. a $80 \mathrm{wt} \%$ (PHPS) $/ 20 \mathrm{wt} \%$ (DBE) solution, and its derivative (DTG); one can observe that a total weight loss about $37 \%$ is observed after pyrolysis to $1300{ }^{\circ} \mathrm{C}$. Such weight loss appears to be associated to two main effects taking place at about $150{ }^{\circ} \mathrm{C}$ and $300^{\circ} \mathrm{C}$. At higher

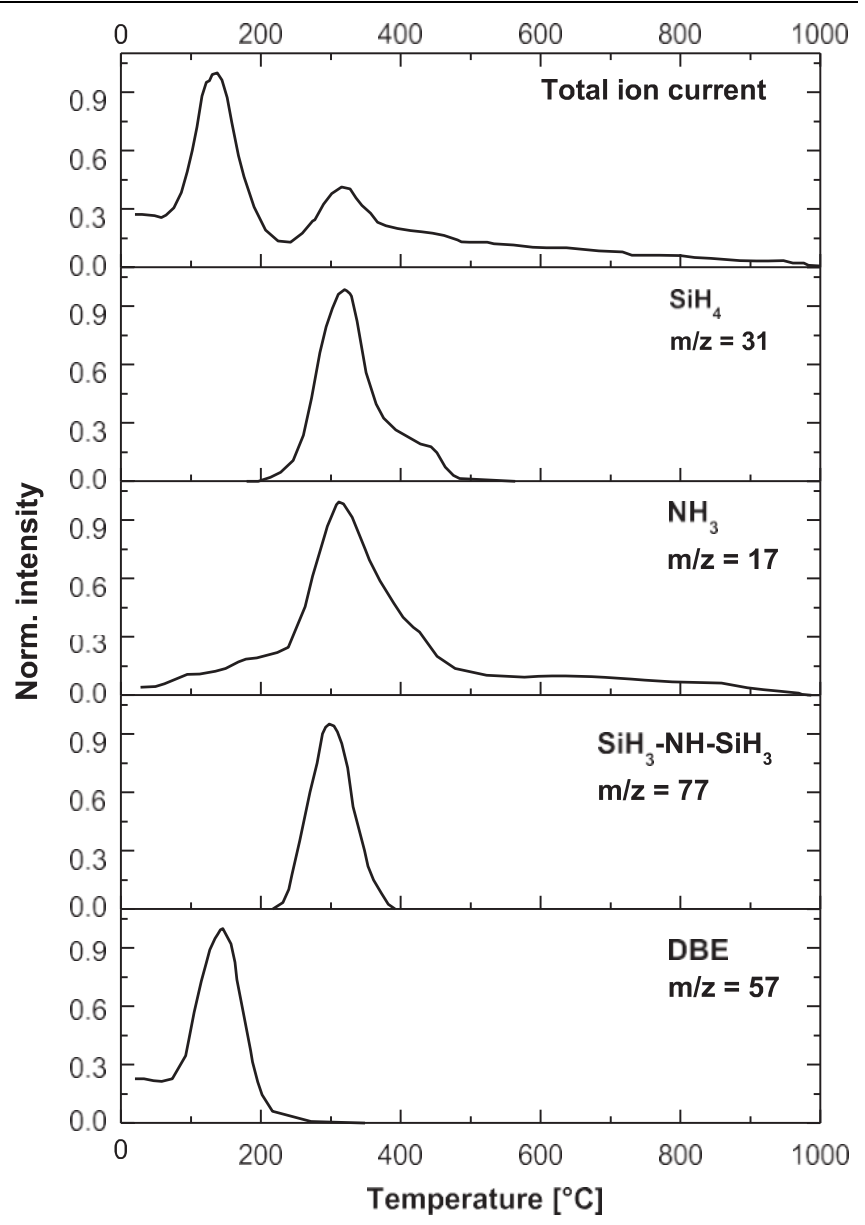

Figure 2. MS signals as a function of the temperature for the main components of the fumes evolved from the decomposition/ evaporation of the PHPS/DBE solution (heating rate $=10^{\circ} \mathrm{C} \mathrm{min}-1$, He atmosphere).

temperatures, no thermal effects are detected and the weight change is already achieved at $800{ }^{\circ} \mathrm{C}$.

The MS analysis of the gases evolved during the TGA are reported in figure 2 and points out two main thermal effects which are strictly bounded to the ones observed in DTG. In particular, the total ion current (TIC) shows two maxima at about $140{ }^{\circ} \mathrm{C}$ and $320^{\circ} \mathrm{C}$. The first one is associated to DBE evolution, which starts from room temperature and ends at about $210^{\circ} \mathrm{C}$. The second TIC signal is related to the evolution of silane $\left(\mathrm{SiH}_{4}\right)$, ammonia $\left(\mathrm{NH}_{3}\right)$ and $\mathrm{SiH}_{3}-$ $\mathrm{NH}-\mathrm{SiH}_{3}$.

Figure 3 shows the XRD patterns of the specimens pyrolyzed in the temperature range from $950^{\circ} \mathrm{C}$ to $1250^{\circ} \mathrm{C}$. Samples treated at $950{ }^{\circ} \mathrm{C}$ are x-ray amorphous. After a pyrolysis at $1050{ }^{\circ} \mathrm{C}$, a very broad peak tends to emerge around $33^{\circ}$ and the materials treated at 1150 and $1250{ }^{\circ} \mathrm{C}$ show the presence of three broad peaks at $2 \theta=33.16^{\circ}$; $55.54^{\circ}$ and $69.59^{\circ}$ which can be assigned to Si nanocrystals (ICSD 60385), with an estimated average volume-weighted crystallite size of 3.2 and $3.8 \mathrm{~nm}$, respectively. Nonetheless, an amorphous background is still present at such high treating temperatures which can be tentatively associated with the 


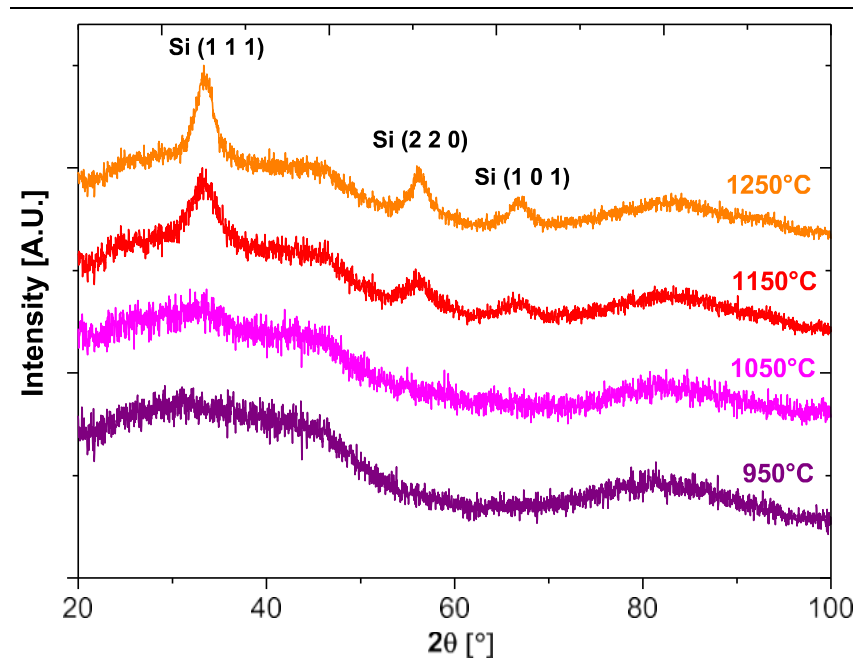

Figure 3. XRD patterns of the samples pyrolyzed at different temperatures.

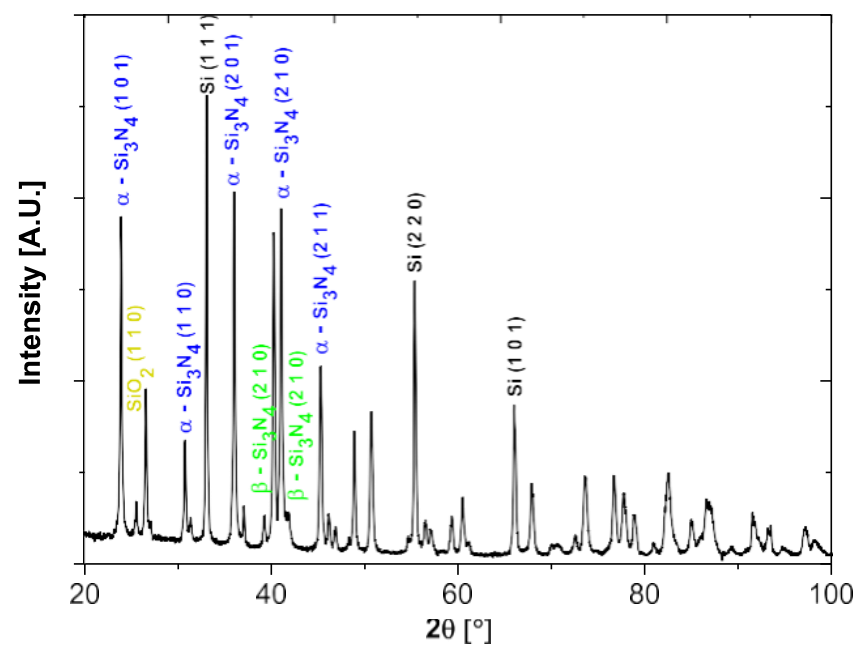

Figure 4. XRD pattern of a completely crystallized sample (treated at $1400{ }^{\circ} \mathrm{C}$ for $2 \mathrm{~h}$ ).

Table 1. Crystallographic phase composition for sample treated at $1400{ }^{\circ} \mathrm{C}$ as derived from XRD quantitative analysis (wt $\%$ ).

\begin{tabular}{lccc}
\hline$\alpha-\mathrm{Si}_{3} \mathrm{~N}_{4}$ & $\beta-\mathrm{Si}_{3} \mathrm{~N}_{4}$ & $\mathrm{Si}$ & $\mathrm{SiO}_{2}$ \\
\hline 80.6 & 4.2 & 13.3 & 1.9 \\
\hline
\end{tabular}

amorphous silicon nitride $\left(\mathrm{Si}_{3} \mathrm{~N}_{4}\right)$ matrix where the nanocrystals are embedded.

To confirm the phase composition of the amorphous matrix, the samples were annealed at $1400^{\circ} \mathrm{C}$ for $2 \mathrm{~h}$, to allow a complete matrix crystallization. The XRD spectrum, reported in figure 4 , shows the strong crystalline reflections of $\alpha-\mathrm{Si}_{3} \mathrm{~N}_{4}$ (ICSD 6004), a marginal content of $\beta-\mathrm{Si}_{3} \mathrm{~N}_{4}$ $(<4 \mathrm{wt} \%)\left(\right.$ ICSD 8263) and $\mathrm{SiO}_{2}(<2 \mathrm{wt} \%)$ (ICSD 47219)

and, again, the presence of well-crystallized silicon. The results of the quantitative analysis are summarized in table 1.

The presence of silicon naonocrystals in the pyrolized samples is confirmed by the HR-STEM micrographs and by
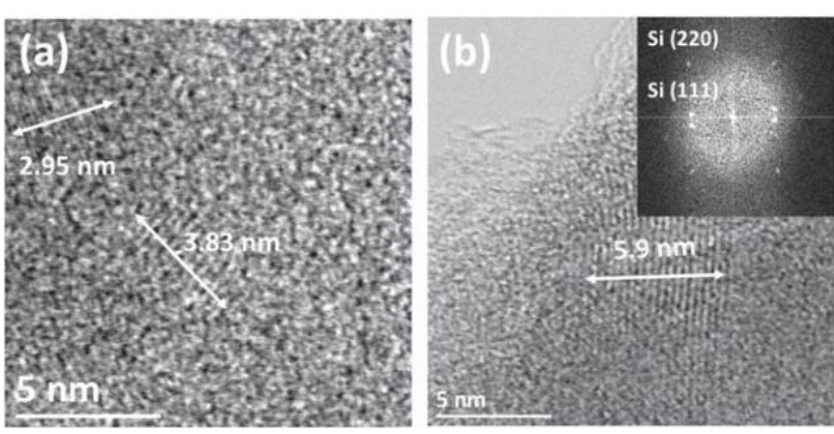

Figure 5. HR-STEM micrographs showing the presence of Si nanoclusters in the samples treated at $1050{ }^{\circ} \mathrm{C}$ (a), and $1250{ }^{\circ} \mathrm{C}$ (b) The inset shows the FFT image of the sample treated at $1250^{\circ} \mathrm{C}$.

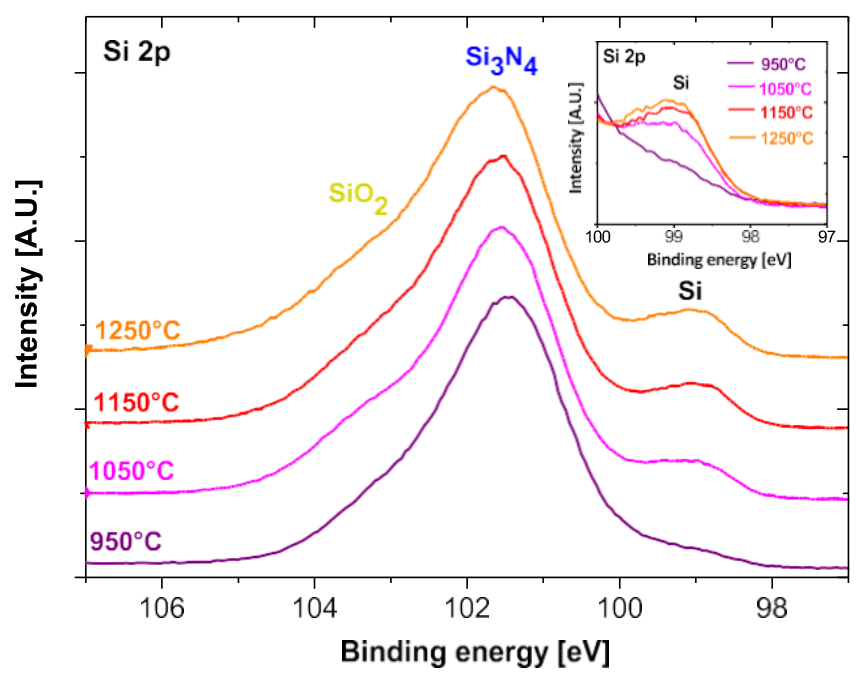

Figure 6. XPS Si 2p spectra obtained on samples pyrolyzed at different temperatures.

the corresponding fast Fourier transform patterns (figure 5). The crystallite size increases with the treating temperature.

The trend of the XPS Si $2 p$ spectra as a function of the temperature is reported in figure 6 . The spectra point out that silicon is present in three different chemical states namely, $\mathrm{Si}_{3} \mathrm{~N}_{4}$ at $101.6 \mathrm{eV}, \mathrm{SiO}_{2}$ at $103.5 \mathrm{eV}$ and $\mathrm{Si}$ at $99.2 \mathrm{eV}$. One can observe that the intensity of the component assigned to $\mathrm{Si}$ clearly increases with the treating temperature, consistently with the observed Si crystallization detected by XRD. However, the intensity of the Si peak of the specimens pyrolyzed at $1150{ }^{\circ} \mathrm{C}$ and $1250{ }^{\circ} \mathrm{C}$ is substantially the same, as pointed out by the inset in figure 6 .

Figure 7 shows the results of the micro-Raman mapping of the nanocomposites. Each of the three points at each temperature is the average position of the Raman peak mapped on about 120 points taken over an area of about $30 \times 30 \mu \mathrm{m}$ on single grains, while the error bars are the standard deviation of the peak position. Standard deviations assume rather large values on all samples, independently on the annealing temperature (albeit they decrease with the annealing temperature). This fact suggests that the local environment of the nc-Si is not homogeneous and that below $1150{ }^{\circ} \mathrm{C}$ the majority of the spots excite amorphous regions, while at temperature above $1150^{\circ} \mathrm{C}$, the crystalline phase 


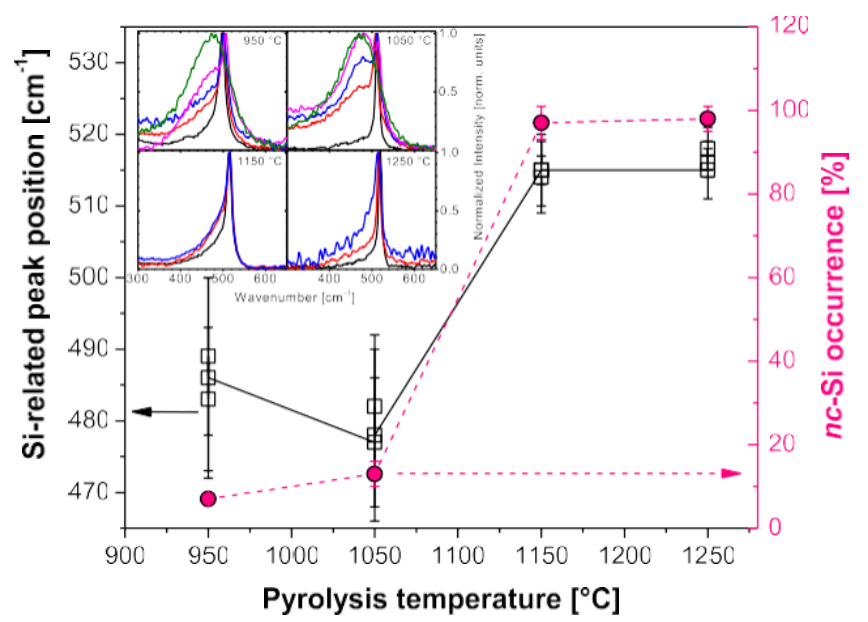

Figure 7. Left axis: Si-related Raman peak position as a function of the pyrolysis temperature. For samples annealed at $950{ }^{\circ} \mathrm{C}$ and $1050^{\circ} \mathrm{C}$ the position of the broad amorphous band is reported on the figure, while the crystalline Si-peak energy is shown for samples annealed above $1100^{\circ} \mathrm{C}$. Right axis: occurrence of the nc-Si peak in the analyzed micro-Raman spots is reported, as well. The inset shows representative nc-Si Raman lineshapes of samples annealed at different temperatures'.

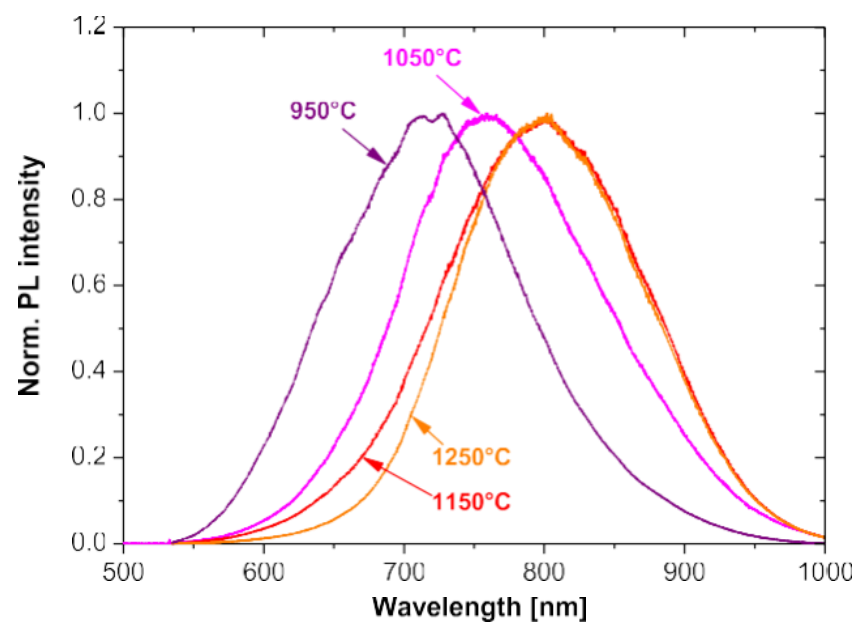

Figure 8.nc-Si@a-SiN $x$ photoluminescence spectra as a function of the pyrolysis temperature (excitation wavelength $=532 \mathrm{~nm}$ ).

dominates and it shows the typical silicon Raman peak [6770]. The inset of figure 7 reports representative line- shapes found at the different annealing temperatures. The average value of the Raman peak (left axis) represents the position of the broad amorphous band for samples annealed below $T_{\text {th }}$ (with $1050<T_{\mathrm{th}}<1150^{\circ} \mathrm{C}$ ), while it indicates the

position of the crystalline peak for those treated at $T>T_{\text {th }}$ (as indicated by the right axis they represent the majority of the peaks in the two cases, respectively). Since the Raman signal shows largely different intensity on the excited domains, we choose a rather large laser intensity (about $10 \mathrm{~mW} \mathrm{\mu m}^{-2}$ ) to obtain reasonable signal-to-noise ratio on each of the investigated spots. Thus, all Raman peaks are blue-shifted by about $4-5 \mathrm{~cm}^{-1}$ compared to their asymptotic signal measured at zero power. We check that this shift is perfectly reversible and

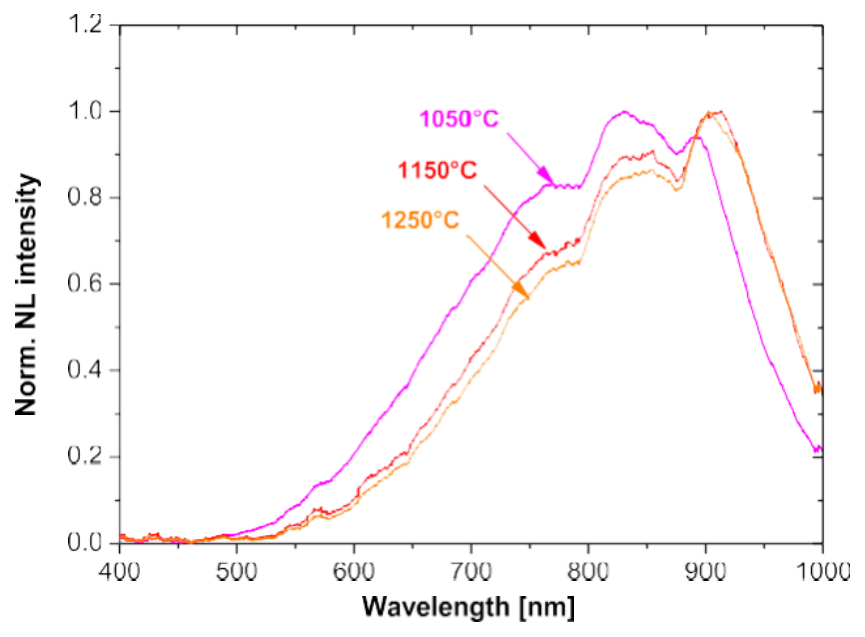

Figure 9.nc-Si@a-SiN $x$ nonlinear photoemission spectra as a function of the pyrolysis temperature (excitation wavelength $=1550 \mathrm{~nm}$, peak power $=250 \mathrm{~W}$ ).

that we are not heat-inducing modifications in the material (data not shown).

PL spectra of the pyrolyzed samples are reported in figure 8 (excitation wavelength $532 \mathrm{~nm}$ ). One can observe the presence of a strong luminescence peak in the red-near infrared region. In our samples, the PL peak clearly red-shifts as temperature increases from $950{ }^{\circ} \mathrm{C}$ to $1150{ }^{\circ} \mathrm{C}$; temperatures greater than $1150^{\circ} \mathrm{C}$ does not further shift the PL. The PL maxima are in detail located at 720,760 and $800 \mathrm{~nm}$ for the samples treated at $950^{\circ} \mathrm{C}, 1050^{\circ} \mathrm{C}$ and $1150^{\circ} \mathrm{C} / 1250^{\circ} \mathrm{C}$, respectively.

To check the robustness of the nc-Si in nitride matrix against intense optical excitation we perform a preliminary measure to verify the presence of nonlinear effects and to check for the stability of the nc-Si. Figure 9 shows the spectra of TPA stimulated PL emission. As for the linear PL, the maximum of the spectra shifts with the annealing temperature and the spectra of the samples pyrolyzed at $1150{ }^{\circ} \mathrm{C}$ and $1250{ }^{\circ} \mathrm{C}$ are substantially identical. The spectrum of the specimen treated at $950{ }^{\circ} \mathrm{C}$ is not reported because its optic response was not stable at the used excitation power densities (peak power density of $40 \mathrm{~kW} \mathrm{~cm}{ }^{-2}$ ).

The chemical resistance of the obtained materials was probed by etching the powders in $\mathrm{HF}$ and $\mathrm{NaOH}$ solutions for $48 \mathrm{~h}$. The weight loss was found about $10 \mathrm{wt} \%$ in $\mathrm{HF}$ (regardless the annealing temperature), whereas no detectable weight changes were measured using the caustic soda solution. The PL response after etching was still present, even though the peak shape and position were slightly altered (supplementary material, figure $\mathrm{S} 1$ is available online at stacks.iop.org/NANO/30/255601/mmedia).

\section{Discussion}

The TGA plot in figure 1 shows the presence, during the thermal decomposition of PHPS solution of two main thermal effects at about $150{ }^{\circ} \mathrm{C}$ and $300^{\circ} \mathrm{C}$. The former is attributed 
the solvent evaporation, the latter to the loss of silane $\left(\mathrm{SiH}_{4}\right)$, ammonia $\left(\mathrm{NH}_{3}\right)$ and $\mathrm{SiH}_{3}-\mathrm{NH}-\mathrm{SiH}_{3}$ units. Solvent evaporation is completed at about $210^{\circ} \mathrm{C}$, as confirmed by the MS analysis in figure 2. At such temperature the weight loss from TG is about $15 \mathrm{wt} \%$, lower than the theoretical DBE load in the solution $(20 \mathrm{wt} \%)$. Such deviation is due to the fact that DBE evaporation already started at room temperature under vacuum (see the DBE signal in figure 2), thus part of the solvent evaporates during the TGA chamber preparation before the beginning of the test. At higher temperatures, mainly between $200{ }^{\circ} \mathrm{C}$ and $400{ }^{\circ} \mathrm{C}$, redistribution reactions between $\mathrm{Si}-\mathrm{H}$ and $\mathrm{Si}-\mathrm{N}$ take place leading to the formation of volatile species such as $\mathrm{SiH}_{4}, \mathrm{SiH}_{3}-\mathrm{NH}-\mathrm{SiH}_{3}$ and $\mathrm{NH}_{3}$. It should be mentioned that redistribution reactions do not cause an increase of the crosslinking degree of the material. Indeed, the transformation from the pre-ceramic to the ceramic material should occur through radical reaction involving the breakage of $\mathrm{Si}-\mathrm{H}$ and $\mathrm{N}-\mathrm{H}$ bond and the formation of new $\mathrm{Si}-\mathrm{N}$ and $\mathrm{Si}-\mathrm{Si}$ bonds with $\mathrm{H}_{2}$ release:

$$
\begin{gathered}
\text { ○ } \mathrm{Si}-\mathrm{H} \square \text { ○ } \mathrm{Si}+\mathrm{H} . \\
=\mathrm{N}-\mathrm{H} \square=\mathrm{N} \cdot+\mathrm{H} . \\
{ }^{\circ} \mathrm{Si}+\cdot \mathrm{N}=\square^{\circ} \mathrm{Si}-\mathrm{N}= \\
{ }^{\circ} \mathrm{Si}+\cdot \mathrm{Si} \circ \square \mathrm{Si}-\mathrm{Si}^{\circ} \\
\mathrm{H} \cdot+\cdot \mathrm{H} \square \mathrm{H}_{2(\mathrm{~g}) .}
\end{gathered}
$$

The $\mathrm{H}_{2}$ evolution, which certainly occurs during pyrolysis as reported in the literature [71], is not recorded by the MS due to the low sensitivity of our equipment for $m / z$ below 4 .

XRD plots in figure 3 point out that the pyrolysis product is amorphous at low pyrolysis temperatures $\left(950{ }^{\circ} \mathrm{C}-\right.$ $\left.1050^{\circ} \mathrm{C}\right)$, but, when the temperature is increased $\left(1150^{\circ} \mathrm{C}-\right.$ $1250^{\circ} \mathrm{C}$ ), Si nanodots crystallization occurs. The nanocrystals are still embedded in an amorphous matrix, as confirmed by the broad features in the XRD patterns of the samples treated at $1150{ }^{\circ} \mathrm{C}$ and $1250{ }^{\circ} \mathrm{C}$. The matrix contains few oxygen contamination, as confirmed by the XRD spectrum of the sample pyrolized at $1400{ }^{\circ} \mathrm{C}$ (figure 4 ) which shows $\alpha-\mathrm{Si}_{3} \mathrm{~N}_{4}$ and $\mathrm{Si}$ with only traces of and $\beta-S i{ }_{34}$ and crystalline silica.

XPS analysis, reported in figure 6, confirms the precipitation nc-Si from the silicon nitride matrix. As a matter of fact, $\mathrm{Si}$ signal at $99.2 \mathrm{eV}$ is detected in all the tested specimens but it progressively increases with the annealing temperature, thus pointing out the thermally-activated formation of $\mathrm{nc}-\mathrm{Si}$. The $\mathrm{SiO}_{2}$ shoulder at about $103.5 \mathrm{eV}$ is likely associated to surfaces contaminations, indeed very few silica has been detected on the completely crystallized sample (figure 4). A further proof of the nc-Si formation is given by the Raman spectra, showing the characteristic features of nanocrytalline silicon [67-70] at about $500 \mathrm{~cm}^{-1}$ (pyrolysis at $950^{\circ} \mathrm{C}$ and $1050^{\circ} \mathrm{C}$ ) and $515 \mathrm{~cm}^{-1}$ (pyrolysis at $1150{ }^{\circ} \mathrm{C}$ and $1250{ }^{\circ} \mathrm{C}$ ).

To understand the nanocomposite formation one should consider that the nominal composition of the ceramic obtained through PHPS decomposition-assuming that only $\mathrm{H}_{2}$ is removed-is $\mathrm{SiN}$ ( $\mathrm{Si}$ to $\mathrm{N}$ ratio 1:1), PHPS being constituted by linear chains of $\left(-\mathrm{SiH}_{2}-\mathrm{NH}-\right)$ units. Indeed, such stoichiometry is not expected from the $\mathrm{Si} / \mathrm{N}$ phase diagram, stoichiometric silicon nitride having a chemical formula $\mathrm{Si}_{3} \mathrm{~N}_{4}$. Therefore, it is possible to obtain a 'siliconrich silicon nitride' from the PHPS thermal decomposition. It is however worth mentioning that some deviations from the exact $\mathrm{Si}: \mathrm{N}$ ratio 1:1 are expected because of the evolution of $\mathrm{SiH}_{4}, \mathrm{NH}_{3}$ and $\mathrm{SiH}_{3}-\mathrm{NH}-\mathrm{SiH}_{3}$ during pyrolysis, thus we will refer to the pyrolysis product as $\mathrm{Si}_{y} \mathrm{~N}_{4}$ (with $y>3$ ).

When the annealing temperature is low the diffusion kinetics are not fast enough to produce a complete phase separation and a homogenous amorphous matrix is obtained with composition $\mathrm{Si}_{y} \mathrm{~N}_{4}$. In such disordered network, the silicon chemical bonds might be partially saturated through the formation of $\mathrm{Si}-\mathrm{Si}$ covalent bonds, the material being nitrogen deficient.

However, as temperature increases clusters of silicon atoms bonded only with other silicon start to be formed. Hence, the matrix becomes progressively more stoichiometric and, more important, nc-Si nucleates. The silicon nanodots growth is therefore ruled by a phase separation reaction (exsolution) taking place in the silicon-abundant amorphous matrix:

$$
\mathrm{Si}_{y} N_{4} \square \mathrm{Si}_{3} N_{4}+(y-3) \mathrm{Si} \text {; with } y>3 .
$$

The stoichiometric reaction, starting from a matrix with the nominal composition $\mathrm{SiN}$, predicts a $\mathrm{Si}$ load in the composite of $15.9 \mathrm{wt} \%$; such value appears in rather good agreement with the quantitative XRD analysis (spectrum in figure 3 ), which points out a Si content of $13.3 \mathrm{wt} \%$. Hence, we can suggest that the ceramic obtained through PHPS decomposition has a Si to $\mathrm{N}$ ratio not far from the nominal one (1:1); in other words, the evolution of $\mathrm{SiH}_{4}, \mathrm{NH}_{3}$ and $\mathrm{SiH}_{3}-\mathrm{NH}-$ $\mathrm{SiH}_{3}$ during the thermal treatment does not cause a strong deviation from the SiN stoichiometry. Above $1000{ }^{\circ} \mathrm{C}$ and up to $1300{ }^{\circ} \mathrm{C}$ the TGA does not show any weight loss confirming that the observed matrix crystallization occurs without any decomposition or reduction reaction.

$\mathrm{Nc}-\mathrm{Si}$ already start to form at $950{ }^{\circ} \mathrm{C}-1050{ }^{\circ} \mathrm{C}$, as highlighted by the shoulder on the XPS spectra at about $99.2 \mathrm{eV}$ that is associated to $\mathrm{Si}-\mathrm{Si}$ bonds. This is consistent with the presence of the Raman feature at about $500 \mathrm{~cm}^{-1}$, which points out the existence of $\mathrm{Si}$ nanoclusters. A further confirmation of the presence of $\mathrm{nc}-\mathrm{Si}$ is given by the TEM micrographs of the sample annealed at $1050{ }^{\circ} \mathrm{C}$ (figure 5). However, the large scattering of the micro-Raman peak position in these samples suggests the coexistence of nanocrystals with broad size distribution. Such dispersion of the crystallite size in the low-annealing temperature materials seems consistent with the XRD and HR-STEM analysis. As a matter of fact, HR-STEM micrographs revealed the presence of some 'quite large' crystals, in the order of $3 \mathrm{~nm}$, in the sample treated at $1050{ }^{\circ} \mathrm{C}$ (figure 5), whose XRD spectrum showed only amorphous features (figure 3 ). This difference is likely due to the better sensitivity of HR-STEM to large crystallites, whereas sub-nanometric clusters are difficult to be observed. This is also due to the low TEM contrast between nc-Si and the silicon nitride matrix, which makes very difficult the identification of the smallest Si nanocrystals. Moreover the micro-Raman nc-Si signal, detected only in about $10 \%$ of the tested regions on the samples treated at 950 and 
$1050^{\circ} \mathrm{C}$, is consistent with the existence some microstructural inhomogeneity. The origin of this feature is not completely clear; however one can propose that it may be associated to small variations of the ceramic composition during pyrolysis ( i.e., different release rate of the gasses from the surface and the core of the material) or to preferential nanocrystals nucleation in determined loci (i.e. surface-assisted nucleation). Further, studies are needed to clarify this effect.

When the treating temperature increases the phase separation proceeds and the Si clusters growth, thus increasing the XPS signal at $99.2 \mathrm{eV}$ and producing clear nanocrystalline features in the XRD spectra. This causes also the Raman peak shift from $500 \mathrm{~cm}^{-1}$ (pyrolysis at $950{ }^{\circ} \mathrm{C}-$ $1050{ }^{\circ} \mathrm{C}$ ) to $515 \mathrm{~cm}^{-1}$ (pyrolysis at $1150{ }^{\circ} \mathrm{C}-1250{ }^{\circ} \mathrm{C}$ ), which points out an increase of the crystals size [67-70] with the treating temperature. Finally, if the pyrolysis temperature is higher than $1150{ }^{\circ} \mathrm{C}$ both XRD, Raman and XPS spectra get stabilized: the crystallite size, detected by XRD, and the intensity of the XPS peak at $99.2 \mathrm{eV}$ are substantially the same for the samples treated at $1150{ }^{\circ} \mathrm{C}$ and $1250{ }^{\circ} \mathrm{C}$. This points out that: (i) the silicon precipitation from the nonstoichiometric amorphous matrix is almost completed at $1150{ }^{\circ} \mathrm{C}$ and (ii) the obtained material presents an excellent thermal stability, the nanocrystals size being substantially unvaried between $1150{ }^{\circ} \mathrm{C}$ and $1250{ }^{\circ} \mathrm{C}$. Indeed, if one assumes that the $\mathrm{Si}$ precipitation from the matrix is already completed at $1150{ }^{\circ} \mathrm{C}$, the only coarsening mechanism becomes Oswald ripening which is likely slower than the exsolution process.

The origin of the PL from nc-Si in nitride matrix is debated since long time. The simple quantum-in-a-box problem predicts a redshift of the energy level of nc-Si embedded in nitride matrix compared to the oxide case (since the smaller energy gap of the former). But the vast majority of publications on $\mathrm{nc}-\mathrm{Si}$ in nitride synthesize the samples by CVD techniques and the size of the nc-Si is defined by the thickness of the silicon rich layer. Thus strong interfacial stress develop at each interface and it is known that mechanical stress heavily affect the optical properties of the nanoparticles by increasing the quantum confinement effect [72]. In fact, a recent publication demonstrated that nc-Si capped with silicon nitride layer show the typical PL of silicon quantum dots [73]. Curiously, despite the large difference between what would be expected from fundamental quantum mechanics and the experimental results, several works still use the typical equation that correlates the increase of the band gap with the inverse of the square of the nc-Si size (which, at this point, is nothing more than a phenomenological power law).

Our optical analysis is well-aligned with the structural characterization and it supports the basics results expected for nc-Si embedded in a dielectric matrix:

i. The PL and NL peaks move toward higher wavelength when the treating temperature increases: this is a typical manifestation of the quantumconfinement effect, where the band gap (and the emitted photon energy) decreases when the crystallite size is increased [5, 44, 46, 74-76]; albeit it might be mediated by surface states. As for the above reported structural analysis, a stabilization of the optical signals is obtained when the pyrolysis temper- ature is above $1150{ }^{\circ} \mathrm{C}$, confirming, once again, a structural stabilization above such temperature.

ii. PL peaks are slightly red-shifted compared to the traditional PL spectra obtained from similar sized nc-Si in $\mathrm{SiO}_{2}$ matrix [77, 78]. Although qualitative, such result supports the smaller confinement of excitons in nitride compare to oxides. Given the complex structure of radiative defects in nitride matrix, we cannot exclude completely their role from the emission but both the structural analysis and the optical characterization points out the typical response of crystalline nc-Si. Yet, it is worth noting that the PL peaks fall well beyond the typical region of nitride luminescent defects and cannot be ascribe to them [52] (at least for the samples treated at $1050{ }^{\circ} \mathrm{C}, 1150{ }^{\circ} \mathrm{C}$ and $1250{ }^{\circ} \mathrm{C}$ ). Thus we suggest our synthesis route might be appealing to further study to definitively clarify fundamental aspects of crystalline nc-Si in amorphous silicon nitride matrix. However, the large blue shift of the PL from samples annealed at $950{ }^{\circ} \mathrm{C}$ and its limited stability under large excitation fluences (see nonlinear characterization below) suggest that this signal might partially originate from defects or defect clusters that disappear at higher annealing temperatures.

A preliminary check of the NL optical properties of this material is reported in figure 9 and points out that the obtained nanocomposites, excluding the one pyrolyzed at $950{ }^{\circ} \mathrm{C}$, are suitable for nonlinear optical applications. The PL was stimulated by TPA mechanism by exciting the sample with a IR pulsed laser at power density of about $40 \mathrm{~kW} \mathrm{~cm}^{-2}$. All samples but the one annealed at the lowest temperature show a bright and stable visible PL under IR pumping, scaling at lower wavelength when increasing the pyrolysis temperature. The long tail at shorter wavelengths might be due to multiphoton processes and radiative paths mediated by defects; while the complex shape of the nonlinear PL spectra requires a careful investigation and the optimization of the synthesis to produce samples with less defects. Albeit this is a preliminary result obtained on powders, the bright PL and its very good stability, confirm that the NL properties of the nc-Si are not quenched by the synthesis methods and the samples are highly stable even under high pump fluences, probably because of the highly refractory properties of the silicon nitride matrix.

The chemical resistance was found to be outstanding both in $\mathrm{HF}$ and $\mathrm{NaOH}$ solutions. Such chemical environments would cause an extremely rapid dissolution of the commonly produced nc-Si@a-SiO obtained in this work resisted for a long time ( $48 \mathrm{~h})$ in concentrated solutions. Also the PL response after etching in such severe conditions was still maintained. The obtained materials are therefore characterized by superior chemical properties and could operate in extremely harsh environments.

\section{Conclusions}


In this work we show, for the first time, the direct nucleation of nc-Si embedded in a silicon nitride matrix. We exploit the pyrolysis of a pre-ceramic polymer (perhydropolysilazane) in protective atmosphere to obtain highly luminescent nanocomposites. We characterize the material both structurally and optically and we show that nc-Si maintains both its linearand nonlinear optical properties also when surrounded by a nitride phase. All samples show a bright PL that shifts with the annealing temperature accordingly to the quantum confinement effect and that nc-Si shows intense nonlinear response. Albeit on a preliminary level, these two evidences support the idea that nc-Si formed from the pyrolysis of a pre-ceramic polymer maintain the basic optical properties as for $\mathrm{nc}-\mathrm{Si}$ nucleated in silica matrix. Moreover, we show that nitride composites have a much stronger chemical resistance to both acidic and basic environments, where the 'traditional' oxide based silicon nanomaterials are corroded.

Unfortunately neither can we perform time resolved measurements since the samples are not of optical quality, nor we can quantify the PL yield. Thus further characterizations are needed to definitively unveil the origin of the PL from ncSi embedded in bulk amorphous nitride matrix free from the interfacial stress that is surely induced in thin multilayer structures and that might be significantly different from the interfacial stress between the single nc-Si and the amorphous, bulk nitride surroundings.

Our synthesis greatly eases the production of nitride embedded nc-Si and it will contribute to stimulate both fundamentals as well as applied science to produce high quality nc-Si easily engineered into active components (such as large area films, fibers and others). Once optimized, this synthesis route would allow a massive, rapid, flexible and easy production of nc-Si in $\mathrm{SiN}_{x}$, substantially surpassing the productivity and shape limitations of the traditional synthesis based on physical or chemical vapor deposition methods.

\section{References}

[1] Canham L 2000 Gaining light from silicon Nature 408 411-2

[2] Priolo F, Gregorkiewicz T, Galli M and Krauss T F 2014 Silicon nanostructures for photonics and photovoltaics Nat. Nanotechnol. 9 19-32

[3] Beard M C, Knutsen K P, Yu P, Luther J M, Song Q, Metzger W K, Ellingson R J and Nozik A J 2007 Multiple exciton generation in colloidal silicon nanocrystals Nano Lett. 7 2506-12

[4] Švrček V, Yamanari T, Shibata Y and Kondo M 2011 Tailoring of hybrid silicon nanocrystal-based bulk heterojunction photovoltaic properties upon nanocrystal laser processing in liquid medium Acta Mater. 59 764-73

[5] Mazzaro R, Romano F and Ceroni P 2017 Long-lived luminescence of silicon nanocrystals: From principles to applications Phys. Chem. Chem. Phys. 19 26507-26

[6] Chen X, Liu Y and Ma Q 2018 Recent advances in quantum dot-based electrochemiluminescence sensors $J$. Mater. Chem. C 6 942-59

[7] Gonzalez C M and Veinot J G C 2016 Silicon nanocrystals for the development of sensing platforms J. Mater. Chem. C 4 4836-46

[8] Kojima T, Sugimoto H and Fujii M 2018 Size-dependent photocatalytic activity of colloidal silicon quantum dot J. Phys. Chem. C 122 1874-80

[9] Dey P P and Khare A 2017 Nonlinear optical and optical limiting response of PLD nc-Si thin films J. Mater. Chem. C 5 12211-20

[10] Wu C-L, Lin Y-H, Cheng C-H, Su S-P, Huang B-J, Chang J-H, Wu C-I, Lee C-K and Lin G-R 2016 Enriching Si quantum dots in a Si-rich $\mathrm{SiN}_{x}$ matrix for strong X(3) optical nonlinearity J. Mater. Chem. C 4 1405-13

[11] Prakash G V, Cazzanelli M, Gaburro Z, Pavesi L, Iacona F, Franzò G and Priolo F 2002 Nonlinear optical properties of silicon nanocrystals grown by plasma-enhanced chemical vapor deposition J. Appl. Phys. 91 4607-10

[12] Vijayalakshmi S, Shen F and Grebel H 1997 Artificial dielectrics: nonlinear optical properties of silicon nanoclusters at $\lambda=532 \mathrm{~nm}$ Appl. Phys. Lett. 7I 3332-4

[13] Sharifi H, Hamidi S M and Navi K 2017 All-optical photonic crystal logic gates using nonlinear directional coupler Photonics Nanostruct.-Fundam. Appl. 27 55-63

[14] Liu Q, Gao S, Li Z, Xie Y and He S 2011 Dispersion engineering of a silicon-nanocrystal-based slot waveguide for broadband wavelength conversion Appl. Opt. 50 1260-5

[15] Bisadi Z et al 2015 Silicon nanocrystals for nonlinear optics and secure communications Phys. Status Solidi Appl.Mater. Sci. 212 2659-71

[16] Erogbogbo F, Yong K, Roy I, Xu G, Prasad P N and Swihart M T 2008 Biocompatible luminescent silicon ACS Nano 2 873-8

[17] Park J H, Gu L, Von Maltzahn G, Ruoslahti E, Bhatia S N and Sailor M J 2009 Biodegradable luminescent porous silicon nanoparticles for in vivo applications Nat. Mater. 8 331-6

[18] Sakiyama M, Sugimoto H and Fujii M 2018 Long-lived luminescence of colloidal silicon quantum dots for timegated fluorescence imaging in the second near infrared window in biological tissue Nanoscale 10 13902-7

[19] Fanizza E et al 2016 Highly selective luminescent nanostructures for mitochondrial imaging and targeting Nanoscale 8 3350-61

[20] Ahire J H, Wang Q, Coxon P R, Malhotra G, Brydson R, Chen R and Chao Y 2012 Highly luminescent and nontoxic amine-capped nanoparticles from porous silicon: synthesis and their use in biomedical imaging ACS Appl. Mater. Interfaces 4 3285-92

[21] Xu Z, Wang D, Guan M, Liu X, Yang Y, Wei D, Zhao C and Zhang H 2012 Photoluminescent silicon nanocrystal-based multifunctional carrier for $\mathrm{pH}-$ regulated drug delivery $A C S$ Appl. Mater. Interfaces 4 3424-31

[22] Ahire J H, Chambrier I, Mueller A, Bao Y and Chao Y 2013 Synthesis of d-mannose capped silicon nanoparticles and their interactions with MCF-7 human breast cancerous cells ACS Appl. Mater. Interfaces 5 7384-91

[23] Cho K S, Park N M, Kim T Y, Kim K H, Sung G Y and Shin J H 2005 High efficiency visible electroluminescence from silicon nanocrystals embedded in silicon nitride using a transparent doping layer Appl. Phys. Lett. 86 1-3 
[24] Royo M, Luca M D and Rurali R 2017 Probing silicon quantum dots by single-dot techniques Nanotechnology 28 72002

[25] Chang C H, Pai Y H, He J H and Lin G R 2010 Wavelengthtunable blue photoluminescence of $<2 \mathrm{~nm} \mathrm{Si}$ nanocrystal synthesized by ultra-low-flow-density PECVD Acta Mater. 58 1270-5

[26] Pavesi L, Dal Negro L, Mazzoleni C, Franzò G and Priolo F 2000 Optical gain in silicon nanocrystals Nature 408 440-4

[27] Yu Y, Fan G, Fermi A, Mazzaro R, Morandi V, Ceroni P, Smilgies D-M and Korgel B A 2017 Size-dependent photoluminescence efficiency of silicon nanocrystal quantum dots J. Phys. Chem. C I 2 I 23240-8

[28] Bruhn B, Brenny B J, Dekker S, Doğan I, Schall P and Dohnalová K 2017 Multi-chromatic silicon nanocrystals Light Sci. Appl. 6 e 17007

[29] Timmerman D, Valenta J, Dohnalová K, De Boer W D A M and Gregorkiewicz T 2011 Step-like enhancement of luminescence quantum yield of silicon nanocrystals Nat. Nanotechnol. 6 710-3

[30] Dal Negro L, Yi J H, Michel J, Kimerling L C, Hamel S, Williamson A and Galli G 2006 Light-emitting silicon nanocrystals and photonic structures in silicon nitride IEEE J. Sel. Top. Quantum Electron. 12 1628-35

[31] Daldosso N et al 2003 Role of the interface region on the optoelectronic properties of silicon nanocrystals embedded in $\mathrm{SiO}_{2}$ Phys. Rev. B 6885327

[32] Ghosh B et al 2014 Hybrid white light emitting diode based on silicon nanocrystals Adv. Funct. Mater. 24 7151-60

[33] Marconi A, Anopchenko A, Pucker G and Pavesi L 2011 Silicon nanocrystal light emitting device as a bidirectional optical transceiver Semicond. Sci. Technol. 2695019

[34] Yao L et al 2016 Efficient silicon quantum dots light emitting diodes with an inverted device structure J. Mater. Chem. C 4 $673-7$

[35] Huang J, Li Q and Shao Z 2018 Fabricating highly luminescent solid hybrids based on silicon nanoparticles: a simple, versatile and green method Nanoscale 10 10250-5

[36] Yuan Z, Nakamura T, Adachi S and Matsuishi K 2017 Luminescence color control and quantum-efficiency enhancement of colloidal Si nanocrystals by pulsed laser irradiation in liquid Nanoscale 9 1193-200

[37] Van Sickle A R, Miller J B, Moore C, Anthony R J, Kortshagen U R and Hobbie E K 2013 Temperature dependent photoluminescence of size-purified silicon nanocrystals ACS Appl. Mater. Interfaces 5 4233-8

[38] Marinins A, Zandi Shafagh R, Van Der Wijngaart W, Haraldsson T, Linnros J, Veinot J G C, Popov S and Sychugov I 2017 Light-converting polymer/si nanocrystal composites with stable 60-70\% quantum efficiency and their glass laminates ACS Appl. Mater. Interfaces 9 30267-72

[39] Li D, Jiang Y, Liu J, Zhang P, Xu J, Li W and Chen K 2017 Modulation of surface states by phosphorus to improve the optical properties of ultra-small Si nanocrystals Nanotechnology 28475704

[40] Wu W S, Hao H L, Zhang Y X, Li J, Wang J J and Shen W Z 2018 Correlation between luminescence and structural evolution of colloidal silicon nanocrystals synthesized under different laser fluences Nanotechnology 29025709

[41] Wang D C, Hao H C, Chen J R, Zhang C, Zhou J, Sun J and Lu M 2015 White light emission and optical gains from a Si nanocrystal thin film Nanotechnology 26475203

[42] Mutti P, Ghislotti G, Bertoni S, Bonoldi L, Cerofolini G F, Meda L, Grilli E and Guzzi M 1995 Room-temperature visible luminescence from silicon nanocrystals in silicon implanted $\mathrm{SiO}_{2}$ layers Appl. Phys. Lett. 66 851-3

[43] Sorarù G D, Modena S, Bettotti P, Das G, Mariotto G and Pavesi L 2003 Si nanocrystals obtained through polymer pyrolysis Appl. Phys. Lett. 83 749-51
[44] Zacharias M, Heitmann J, Scholz R, Kahler U, Schmidt M and Bläsing J 2002 Size-controlled highly luminescent silicon nanocrystals: a $\mathrm{SiO} / \mathrm{SiO}_{2}$ superlattice approach Appl. Phys. Lett. 80 661-3

[45] Arduca E, Seguini G, Martella C, Lamperti A, Napolitani E, De Salvador D, Nicotra G, Scuderi M, Spinella C and Perego M 2018 Electronic band structures of undoped and P-doped Si nanocrystals embedded in $\mathrm{SiO}_{2}$ J. Mater. Chem. C 6 119-26

[46] Park N M, Choi C J, Seong T Y and Park S J 2001 Quantum confinement in amorphous silicon quantum dots embedded in silicon nitride Phys. Rev. Lett. 86 1355-7

[47] Volodin V A, Efremov M D, Gritsenko V A and Kochubei S A 1998 Raman study of silicon nanocrystals formed in $\mathrm{SiN}_{x}$ films by excimer laser or thermal annealing Appl. Phys. Lett. 731212

[48] Wang Y Q, Wang Y G, Cao L and Cao Z X 2003 Highefficiency visible photoluminescence from amorphous silicon nanoparticles embedded in silicon nitride Appl. Phys. Lett. 83 3474-6

[49] Iacona F, Franzò G and Spinella C 2000 Correlation between luminescence and structural properties of Si nanocrystals J. Appl. Phys. 87 1295-303

[50] Nava G et al 2017 Towards an electronic grade nanoparticleassembled silicon thin film by ballistic deposition at room temperature: the deposition method, and structural and electronic properties J. Mater. Chem. C 3725-35

[51] Gago R, Vázquez L, Cuerno R, Varela M, Ballesteros C and Albella J M 2001 Production of ordered silicon nanocrystals by low-energy ion sputtering Appl. Phys. Lett. 78 3316-8

[52] Goncharova L V, Nguyen P H, Karner V L, D’Ortenzio R, Chaudhary S, Mokry C R and Simpson P J 2015 Si quantum dots in silicon nitride: quantum confinement and defects J. Appl. Phys. II 8224302

[53] Hiller D et al 2014 Absence of quantum confinement effects in the photoluminescence of $\mathrm{Si}_{3} \mathrm{~N}_{4}$-embedded $\mathrm{Si}$ nanocrystals J. Appl. Phys. II 5204301

[54] Zelenina A et al 2013 Structural and optical properties of size controlled Si nanocrystals in $\mathrm{Si}_{3} \mathrm{~N}_{4}$ matrix: the nature of photoluminescence peak shift J. Appl. Phys. II4 184311

[55] Negro L D, Yi J H, Michel J, Kimerling L C, Hamel S, Williamson A and Galli G 2006 Light-emitting silicon nanocrystals and photonic structures in silicon nitride IEEE J. Sel. Top. Quantum Electron. 12 1628-35

[56] Rodriguez-Gòmez A, Garcìa-Valenzuela A, Haro-Poniatowski E and Alonso-Huitròn J C 2013 Effect of thickness on the photoluminescence of silicon quantum dots embedded in silicon nitride films J. Appl. Phys. I I 3233102

[57] Colombo P, Mera G, Riedel R and Sorarù G D 2010 Polymerderived ceramics: 40 years of research and innovation in advanced ceramics J. Am. Ceram. Soc. 93 1805-37

[58] Blanchard C R and Schwadb S T 1994 X-ray diffraction analysis of the pyrolytic conversion of perhydropolysilazane into silicon nitride J. Am. Ceram. Soc. 77 1729-39

[59] Iwamoto Y, Völger W, Kroke E, Riedel R, Saitou T and Matsunaga K 2001 Crystallization behavior of amorphous silicon carbonitride ceramics derived from organometallic precursors J. Am. Ceram. Soc. 84 2170-8

[60] Mera G, Gallei M, Bernard S and Ionescu E 2015 Ceramic nanocomposites from tailor-made preceramic polymers Nanomaterials 5 468-540

[61] Ionescu E, Kleebe H J and Riedel R 2012 Silicon-containing polymer-derived ceramic nanocomposites (PDC-NCs): Preparative approaches and properties Chem. Soc. Rev. 4 I 5032-52

[62] Günthner M, Kraus T, Dierdorf A, Decker D, Krenkel W and Motz G 2009 Advanced coatings on the basis of $\mathrm{Si}(\mathrm{C}) \mathrm{N}$ precursors for protection of steel against oxidation $J$. Eur. Ceram. Soc. 29 2061-8 
[63] Seyferth D, Wiseman G H and Prud'homme C 1983 A liquid silazane precursor to silicon nitride J. Am. Ceram. Soc. 66 C13-4

[64] Lale A, Wasan A, Kumar R, Miele P, Demirci U B and Bernard S 2016 Organosilicon polymer-derived mesoporous 3D silicon carbide, carbonitride and nitride structures as platinum supports for hydrogen generation by hydrolysis of sodium borohydride Int. J. Hydrog. Energy 4I 15477-88

[65] Salameh C, Bruma A, Malo S, Demirci U B, Miele P and Bernard S 2015 Monodisperse platinum nanoparticles supported on highly ordered mesoporous silicon nitride nanoblocks: superior catalytic activity for hydrogen generation from sodium borohydride RSC Adv. 5 58943-51

[66] Lutterotti L, Bortolotti M, Ischia G, Lonardelli I and Wenk H-R 2007 Rietveld texture analysis from diffraction images Z. Krist. I 125-30

[67] Duan Y, Kong J F and Shen W Z 2012 Raman investigation of silicon nanocrystals: Quantum confinement and laserinduced thermal effects J. Raman Spectrosc. 43 756-60

[68] Ossadnik C, Vepřek S and Gregora I 1999 Applicability of Raman scattering for the characterization of nanocrystalline silicon Thin Solid Films 337 148-51

[69] Paillard V, Puech P, Laguna M A, Carles R, Kohn B and Huisken F 1999 Improved one-phonon confinement model for an accurate size determination of silicon nanocrystals J. Appl. Phys. 86 1921-4

[70] Doğan I and van de Sanden M C M 2013 Direct characterization of nanocrystal size distribution using Raman spectroscopy J. Appl. Phys. II4 134310
[71] Funayama O, Nakahara H, Okoda M, Okumura M and Isoda T 1994 Conversion mechanism of polyborosilazane into silicon nitride-based ceramics J. Mater. Sci. 29 4883-8

[72] Cho C, Kang J, Park I and Park S 2017 Enhanced quantum con fi nement in tensile-strained silicon nanocrystals embedded in silicon nitride Curr. Appl. Phys. 17 1616-21

[73] Mandal R, O'Shea K and Anthony R 2018 approach Silicon nitride-capped silicon nanocrystals via a nonthermal dualplasma synthesis approach J. Appl. Phys. 3651303

[74] Wilson W L, Szajowski P F and Brus L E 1993 Quantum confinement in size-selected, surface-oxidized silicon nanocrystals Science 262 1242-4

[75] English D S, Pell L E, Yu Z, Barbara P F and Korgel B A 2002 Size tunable visible luminescence from individual organic monolayer stabilized silicon nanocrystal quantum dotsNano Lett. 2 681-5

[76] Ledoux G, Guillois O, Porterat D, Reynaud C, Huisken F, Kohn B and Paillard V 2000 Photoluminescence properties of silicon nanocrystals as a function of their size Phys. Rev. B 62 15942-51

[77] Wolkin M V, Jorne J, Fauchet P M, Allan G and Delerue C 1999 Electronic states and luminescence in porous silicon quantum dots: the role of oxygen Phys. Rev. Lett. 82 197200

[78] Belyakov V A, Burdov V A, Lockwood R and Meldrum A 2008 Silicon nanocrystals: fundamental theory and implications for stimulated emission Adv. Opt. Technol. 2008279502 